\title{
Stress, sex, and motivated behaviors
}

Abigail Laman-Maharg ${ }^{1,2,3}$ and Brian C. Trainor ${ }^{1,2,3}$

${ }^{1}$ Neuroscience Graduate Group, ${ }^{2}$ Department of Psychology, and ${ }^{3}$ Center for Neuroscience, University of California, Davis, CA, USA

Abbreviated Title: Stress, sex, and motivated behaviors

Associate Editor: Larry Cahill

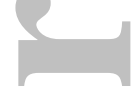

Key Words: social defeat stress, social behavior, drug seeking, mesolimbic dopamine system

Brian C. Trainor

Department of Psychology

1 Shields Ave.

University of California

Davis, CA 95616

bctrainor@ucdavis.edu

ALM Supported by Schwall Fellowship and BCT Supported by NIH MH103322.

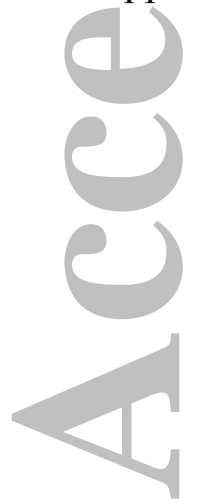

This is the author manuscript accepted for publication and has undergone full peer review but has not been through the copyediting, typesetting, pagination and proofreading process, which may lead to differences between this version and the Version record. Please cite this article as doi:10.1002/jnr.23815. 


\begin{abstract}
Stress is a major risk factor for the development of psychiatric disorders, such as depression, and the development of substance use disorder. Although there are important sex differences in the prevalence of these disorders, the majority of preclinical models used to study stress-induced disorders use males only. Social defeat stress is a commonly used method to induce stress in an ethologically relevant way, but has only recently begun to be used in female rodents. Using these new female models, recent studies have examined how social defeat stress affects males and females differently at the behavioral, circuit, and molecular levels. This review discusses sex differences in the effects of social defeat stress on social behavior and drug seeking behavior, as well as its impact on the mesolimbic dopamine system and the highly connected region of the bed nucleus of the stria terminalis.
\end{abstract}

\title{
Significance Statement
}

Stress-induced disorders, such as anxiety, depression, post-traumatic stress disorder, and substance use disorder are more common in women than in men. Understanding the sex-specific effects of stress on the brain is crucial for the successful development of novel treatments for stress-induced disorders.

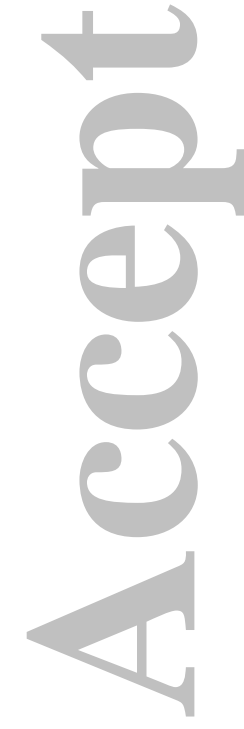


Stress is a major risk factor for the development of psychiatric disorders such as depression, anxiety, and post-traumatic stress disorder. These disorders are frequently comorbid with substance use disorder (Kessler et al., 2005), suggesting possible overlap in underlying mechanisms. At the population level women are twice as likely as men to suffer from anxiety and depression (Kessler, 2003), and women may also be more vulnerable at every phase of the addiction cycle compared to men (Anker \& Carroll, 2011). However, most of the basic research examining the neurobiological mechanisms of these disorders has been conducted with male rodents. For example, social defeat stress is a robust and ethologically relevant way to induce stress in rodents, and this model has produced important discoveries on how stress alters brain circuits modulating behaviors related to stress-induced psychiatric disorders and addiction. The majority of studies have utilized male C57B16 mice or rats. However, the development of social defeat stress protocols in female rats, hamsters, and California mice has created new opportunities to consider sex-differences in how stress impacts the brain. While many neurobiological systems are affected by defeat stress (Buwalda et al., 2005; Hammels et al., 2015), the mesolimbic dopamine system which includes the ventral tegmental area (VTA) and nucleus accumbens (NAc), has emerged as an important pathway mediating the effects of stress on behavior. Additionally, recent data highlight the importance of the bed nucleus of the stria terminalis (BNST) as a critical nucleus modulating the interaction between stress, motivation, and social behavior. Here we review how new models of female social defeat provide novel insights into the mechanisms underlying sex differences in how social stress affects motivated behaviors and the implications for mental health and addiction.

\section{WHAT IS SOCIAL DEFEAT STRESS?}

Social defeat is commonly used as an ethologically relevant stressor in rodents. Specific protocols vary across species and laboratories, with a common thread consisting of aggressive physical contact with a more aggressive individual. In most cases, the focal animal is an intruder in an unfamiliar cage and is unlikely to be aggressive toward the resident. Focal animals are randomly assigned to stress or control conditions, which controls for intrinsic differences in aggressive behavior and competitive ability. Social defeat induces behavioral phenotypes related 
to depression and anxiety such as social withdrawal, submissive behavior, or anhedonia. Interestingly, there is a significant variability in sensitivity to social defeat across species.

In Syrian hamsters (Mesocricetus auratus), a male that experiences a single episode of defeat will show submissive behaviors when faced with a smaller non-aggressive intruder within its own homecage (Cooper et al., 2015). The normal response in this context is aggressive behavior, so this inappropriate submissive behavior has been referred to as "conditioned defeat" (Jasnow \& Huhman, 2001). Similar changes are observed after multiple episodes of defeat (Huhman et al., 2003; Morrison et al., 2011; Jeffress \& Huhman, 2013; Morrison et al., 2014). Repeated episodes of defeat add a different dimension, both in total amount of stress experienced, as well as predictability. For instance, California mice show increased anxiety-like behavior immediately prior to a third episode of defeat stress (Greenberg et al., 2015), presumably induced by conditioned stimuli present in the behavior testing room. Sensory contact is an important component of the most widely used protocols for male C57 mice (Golden et al., 2011) and rats (Vasconcelos et al., 2015). This may be because males in these species are more resistant to social defeat. For example, after a short physical confrontation, a focal mouse is separated from the resident by a clear, perforated divider placed in a shared homecage. This sensory contact protocol is similar to that used by Kudryavtseva and colleagues (Kudryavtseva et al., 1991; Kudryavtseva et al., 2004) who compared the behavioral and neurobiological changes induced by winning and losing aggressive encounters. Recently a witness model of defeat was developed to separate the physical and psychological impact of defeat stress (Sial et al., 2016). A mouse (Warren et al., 2013; Sial et al., 2016) or rat (Patki et al., 2014) that observes its cagemate undergo defeat through a perforated barrier will exhibit some of the same behavioral changes seen in its cagemate that experiences physical stress. These approaches to social defeat stress reliably induce anxiety-like and depression-like behaviors in males, and recently developed protocols have allowed for the study of effects of social defeat in both males and females.

Levels of aggression experienced during social defeat can vary between males and females of the same species, an important consideration when making comparisons between sexes. The California mouse (Peromyscus californicus) is a monogamous species in which females defend territories with males (Ribble \& Salvioni, 1990). Social defeat in California mice has been 
optimized so that on average males and females are exposed to the same number of aggressive interactions across three episodes of defeat (Trainor et al., 2013). Lactating rat dams are used to induce defeat in female rats (Holly et al., 2012; Shimamoto et al., 2015). Although aggression levels of males and lactating dams are typically not compared in the same study, long lasting behavioral changes are induced (Holly et al., 2012; Shimamoto et al., 2015). Interestingly, female Syrian hamsters are more aggressive than males (Payne \& Swanson, 1970), which has facilitated studies of defeat stress in female hamsters. Social defeat stress has been shown to induce long-term changes in brain and behavior in both males and females. This has led to the investigation of how social stress affects responses to natural and drug related rewards at behavioral, circuit, and molecular levels.

\section{EFFECTS OF SOCIAL DEFEAT ON SOCIAL BEHAVIOR}

Social withdrawal is a common symptom of depression in humans, and this is modeled in rodents using the social interaction test. Kudryavtseva and colleagues (Kudryavtseva et al., 1991) were one of the first groups to show that male C57Bl/6 mice subjected to defeat spent less

time exploring a novel mouse compared to unstressed controls. Remarkably, this basic result has been replicated in different labs around the world (Berton et al., 2006; Krishnan et al., 2007; Venzala et al., 2012) and in different species (Trainor et al., 2011). The effects of defeat on social interaction behavior can persist for more than four weeks after the last episode of defeat (Berton et al., 2006; Hollis et al., 2010). This persistent phenotype resembles behavioral changes associated with depression and anxiety, which can linger for years. Finally, reduced social interaction behavior is reversed with chronic, but not acute, antidepressant treatment (Kudryavtseva et al., 1991; Berton et al., 2006; Cao et al., 2010; Warren et al., 2013; Greenberg et al., 2014). Thus, stress-induced reductions in social interaction have strong face and pharmacological validity to social withdrawal behavior observed in stress-induced psychiatric disorders. Examining sex differences in social interaction in response to defeat stress is a useful technique to study sex differences in rodent models of depression and anxiety.

\section{California Mice (Peromyscus californicus)}


Male and female California mice exhibit different behavioral phenotypes in response to social defeat stress. Stressed females, but not stressed males, show decreased social interaction after exposure to 3 consecutive days of social defeat consisting of 7 minutes or 7 attacks (Trainor et al., 2011; Trainor et al., 2013; Greenberg et al., 2014; Greenberg et al., 2015) and this behavioral change is not accompanied by reduced locomotor or exploratory behavior. Similar to male C57B1/6 mice (Berton et al., 2006), stress-induced social withdrawal lasts at least 4 weeks, and there is no effect of estrous cycle or gonadectomy (see Figure 1) (Trainor et al., 2011; Trainor et al., 2013). Stressed females also show decreased biting and chasing and increased attack latency in the resident intruder test (Steinman et al., 2015), as well as decreased investigation time of novel female urine in a habituation-dishabituation test (Trainor et al., 2011).

Although defeat stress does not affect male behavior in the social interaction test, effects of defeat are more prominent when males are tested in a familiar environment. Stressed males exhibit decreased investigation time of novel male urine in the habituation-dishabituation test (Trainor et al., 2011) and increased freezing and escape behavior when tested as residents in the resident intruder test, (Steinman et al., 2015). In contrast to social interaction testing, these tests are conducted in the home cage, suggesting that the environment is a critical factor modulating the effect of defeat on behavior. These results fit well with previous research demonstrating the importance of the environment in the context of winning aggressive encounters. Male California mice that win prior encounters are more likely to win future encounters, even if the intruder is larger (Oyegbile \& Marler, 2005). However, this "winner effect" is only observed when the focal mouse is tested in the home cage (Fuxjager et al., 2009). Previous winning experience has no effect on aggressive behavior in a novel environment. Interestingly, defeat reduces aggression in male crickets and this effect is blocked when a male is transferred to a new environment (Hofmann \& Stevenson, 2000). It's likely that these context-dependent effects of experience on aggression are related to territoriality. Both male California mice and crickets must maintain a territory to reproduce. The context-dependent effects of defeat stress may allow for an individual to compete for resources in a new location after an unsuccessful outcome.

\section{Syrian Hamsters (Mesocricetus auratus)}


The reported effects of social defeat in Syrian hamsters are stronger in males than females (Huhman et al., 2003). This phenomenon is studied primarily through conditioned defeat testing. All male hamsters that experience social defeat will subsequently exhibit conditioned defeat behavior for at least ten days afterwards, and about $60 \%$ of male hamsters will continue to show conditioned defeat for at least 33 days after experiencing social defeat stress (Huhman et al., 2003). Interestingly, dominant male hamsters show less conditioned defeat than subordinates, but controls show an intermediate amount of submissive and defensive behavior and do not differ significantly from either dominants or subordinates (Morrison et al., 2011; Morrison et al., 2012). In these studies hamsters are allowed to establish dominance status on their own. Thus, resilience to defeat could be mediated by either intrinsic factors, the experience of establishing dominance status, or both.

In female hamsters, social defeat stress does not have the same impact on conditioned defeat. Only $28 \%$ of defeated females show conditioned defeat behavior, and, unlike males, all defeated females exhibit normal territorial aggression by the second behavioral test four days after defeat (Huhman et al., 2003). Defeated females tested during late diestrus and proestrus are more likely to exhibit conditioned defeat than females tested during early diestrus or estrus, but even then, the change in behavior is less prolonged than in defeated males (Solomon et al., 2007). Curiously, non-defeated females display normal territorial aggression regardless of hormonal status (Solomon et al., 2007). These results suggest that the estrus cycle plays a small role in the development of conditioned defeat in female hamsters, but by itself cannot explain the sex differences in behavior between defeated males and females.

From an evolutionary perspective it is possible that female hamsters are more resilient to conditioned defeat than males because of their respective reproductive strategies. Field observations indicate there may be important sex differences in the context of how Syrian hamster aggressive encounters are staged (cited in Bath \& Johnston, 2007). Aggressive interactions observed among male hamsters involved two males competing for a female in estrus. However, aggressive interactions among females are thought to occur primarily to defend the burrow, stored food, or pups. Therefore, losing an aggressive interaction could be more costly to females than males. This might result in selection for enhanced aggression in females. 
Interestingly, the link between increased aggression and reduced susceptibility to social stress has also been observed in male California mice.

\section{Mice (Mus musculus) and Rats (Rattus norvegicus)}

Although many research groups have demonstrated that social defeat stress reduces male social interaction behavior in $\mathrm{C} 57 \mathrm{Bl} / 6$, strain differences have been observed with BALB/c mice being more susceptible to defeat (Savignac et al., 2011) and FVB mice being more resilient (Liu et al., 2015). In Wistar (Lukas et al., 2011) and Tyron (Meerlo et al., 1996) rats social defeat also reduces social interaction behavior in males. To date, no study has documented the effects of defeat stress on female social interaction behavior in these species. For rats, the lactating dam model could be used to assess the impact of defeat on female social behavior. For mice, the witness defeat model (Sial et al., 2016) might represent an important tool for assessing how social stress affects female behavior.

\section{EFFECTS OF SOCIAL DEFEAT ON DRUG SEEKING BEHAVIOR}

Drug abuse is affected by a combination of behavioral processes including motivation to obtain the drug (incentive salience) and the rewarding properties of the drug (hedonic impact).

Interestingly, motivation to obtain a drug can be dissociated from the rewarding properties of the drug (Berridge et al., 2009). Therefore, it is important to disentangle these components in studies examining neurobiological mechanisms related to addiction. A common approach for investigating motivation is the self-administration model which typically consists of four phases: acquisition, maintenance, extinction, and reinstatement (Panlilio \& Goldberg, 2007). Animals must first learn to acquire the drug and then maintain self-administration. Drug seeking behavior is usually extinguished after a period of abstinence when the drug is no longer available.

However drug seeking-behavior can be reinstated in a model of relapse by priming (re-exposure to the drug), exposure to drug-associated cues, or exposure stress (Panlilio \& Goldberg, 2007). A second approach to examine the rewarding properties of a drug is conditioned place preference (CPP), in which animals are conditioned to associate the properties of the drug with a specific environment (Bardo \& Bevins, 2000). In this test the drug is administered by the experimenter and so the results are considered to be driven more by reward value of the drug rather than the 
motivation to obtain the drug. Social defeat stress has been shown to affect both motivation to obtain drugs and the rewarding properties.

The effects of defeat on the motivation to obtain drugs such as cocaine have been examined extensively using self-administration. Male rats assigned to four episodes of defeat stress over a 10 day period acquire cocaine self-administration more rapidly than non-stressed controls (Covington \& Miczek, 2005; Yap et al., 2015). In addition, after acquisition of cocaine selfadministration, a brief episode of defeat immediately before drug access increases rates of selfadministration (Miczek \& Mutschler, 1996). In part due to smaller body size, it is more technically challenging to perform self-administration studies in mice. However, a recent study showed that male Swiss Webster mice exposed to 10 days of defeat self-administered significantly more cocaine over 2 hours than controls during a maintenance session (Han et al., 2015). These results indicate that 4 to 10 episodes of defeat stress increases the motivation to acquire cocaine. In contrast, continued exposure to defeat over a longer period of about a month suppresses cocaine administration (Miczek et al., 2011). This suggests that continuous, uncontrollable exposure to defeat may be triggering anhedonia. To measure a change in the value of a reward such as cocaine, CPP assays have proved useful.

In male C57B1/6 mice, defeat stress generally potentiates the CPP for the drug-paired chamber compared to unstressed mice (McLaughlin et al., 2006; Hymel et al., 2014). Defeat also inhibits the extinction of cocaine induced CPP (Montagud-Romero et al., 2015). Finally, social defeat facilitates the reinstatement of cocaine CPP after extinction (Land et al., 2009; Ribeiro Do Couto et al., 2009; Titomanlio et al., 2013; Montagud-Romero et al., 2015). These results indicate that intermittent defeat increases the reward value of cocaine and increases the likelihood that an individual will seek cocaine after a period of abstinence. These results are consistent with clinical data indicating that psychosocial stress is a strong risk factor for relapse after treatment for substance abuse disorders (Sinha, 2008).

The effect of social defeat stress on drug seeking behavior in female rodents has been confined to the lactating rat dam model. Female rats acquire cocaine self-administration more readily than males, an effect that is mediated by estradiol (Jackson et al., 2006). Both male and female rats 
exposed to social defeat self-administered more cocaine than control rats (Haney et al., 1995). Similarly, defeat was found to increase the total number of cocaine infusions in both male and female rats given unlimited access to cocaine (Holly et al., 2012). However, while stressed males stopped cocaine self-administration 12-13 hours into the binge session, females continued to self-administer cocaine for 24 hours. It appears that in female rats, defeat inhibits homeostatic responses that reduce cocaine self-administration in males after 12 hours. These results suggest that longer term observations are required to observe sex difference in the effects of social defeat on the motivation to use cocaine. To our knowledge, no study has examined the effect of social defeat on place preference, extinction or reinstatement in female rodents.

\section{EFFECTS OF SOCIAL DEFEAT ON THE MESOLIMBIC DOPAMINE SYSTEM} Drugs of abuse such as cocaine acutely engage the mesolimbic dopamine system, which, in turn, is an important regulator of social behaviors. Not surprisingly, the mesolimbic dopamine system is strongly impacted by social defeat stress. In addition to short-term effects, social defeat induces a persistent increase in phasic firing of dopamine neurons in the VTA (Krishnan et al., 2007; Cao et al., 2010). In susceptible mice exposed to defeat, the average frequency of neuronal firing increases to about $3.0 \mathrm{~Hz}$ compared to $2.0 \mathrm{~Hz}$ observed in non-defeated controls (Krishnan et al.,2007) This change in activity, especially in VTA neurons projecting to the NAc (Krishnan et al., 2007; Chaudhury et al., 2013) directly contributes to at least some of the behavioral changes induced by defeat.

\section{Short-term effects}

During episodes of social defeat, the mesolimbic dopamine system is activated. For example in male rats dopamine release into the NAc is increased during episodes of defeat (Tidey \& Miczek, 1996). This was an early clue that dopamine release in the NAc was not a simple reward signal. Interestingly, the degree to which VTA dopamine neurons respond to social defeat is topographically organized. Neurophysiology studies of anesthetized rats suggest that ventral VTA dopamine neurons respond more strongly to aversive contexts than dorsal VTA dopamine neurons (Brischoux et al., 2009). This hypothesis is supported in c-fos/tyrosine hydroxylase (TH) immunostaining study of male and female California mice exposed to defeat or control conditions. Female California mice exposed to three episodes of defeat, but not a single episode, 
had more TH/c-fos-positive cells in the ventral (but not dorsal) VTA compared to control females, but defeat did not affect TH/c-fos colocalizations in males (Greenberg et al., 2015). Finally, dopamine in the NAc appears to be critical for the acquisition and expression of conditioned defeat in male hamsters. During a training period, hamsters experienced defeat from a resident aggressor and the next day focal hamsters were tested in a resident-intruder test in which a non-aggressive intruder was placed into the homecage (Gray et al., 2015). Hamsters that received an infusion of the non-specific D1/D2 receptor antagonist cis(z)flupenthixol (3.75 $\mu \mathrm{g})$ into the NAc either before social defeat training or before the resident-intruder test exhibited decreased submissive behavior during testing (Gray et al., 2015). In hamsters that did not experience social defeat, infusions of the antagonist into the NAc resulted in normal aggressive behavior during the resident-intruder test. This indicates that dopamine signaling in the NAc is important in modulating the expression and acquisition of stress-induced conditioned defeat.

\section{Long-term effects}

Exposure to defeat stress also induces long-term changes in the VTA-NAc circuit. Chaudhury et al. (2013) selectively targeted NAc-projecting VTA neurons by injecting a Cre expressing pseudorabies virus into the NAc and a Cre-dependent channel rhodopsin (ChR2) expressing virus into the VTA. The pseudorabies virus was taken up by VTA terminals in the NAc and delivered to VTA cell bodies through retrograde transport. Thus, only the VTA neurons projecting to the NAc expressed the Cre enzyme. This is important because the ChR2 expressing vector contained a double floxed sequence that had to be removed by Cre in order to activate the ChR2. Almost all of the cells expressing ChR2 were dopamine neurons, which allowed the authors to induce phasic firing with optical stimulation. Mice expressing these viruses underwent subthreshold defeat stress ( 2 short episodes in 1 day) that, by itself, does not induce social withdrawal or other depression-like behaviors (Krishnan et al., 2007; Iniguez et al., 2010). Subthreshold defeat plus phasic optical stimulation of VTA dopamine neurons either during defeat or during social interaction induced social withdrawal (Chaudhury et al., 2013). Phasic activation of these same neurons in non-defeated controls had no effect, as did tonic activation in mice assigned to subthreshold defeat. Another group of mice was assigned to chronic social defeat (10 days), which induces phasic firing of VTA dopamine neurons and social withdrawal. A combination of a retrograde Cre-virus and halorhodopsin allowed for the inhibition of these 
hyperactive VTA neurons. Optical inhibition of VTA dopamine neurons projecting to the NAc restored normal levels of social interaction (Chaudhury et al., 2013). It is clear that activation of these neurons is necessary for stress-induced social withdrawal, but their role is complex. Development of depression-like behavior depends both on the specific firing pattern of the neurons and the severity of the previous exposure to stress.

The effects of defeat on the mesolimbic system are long lasting, and some of these effects appear to be mediated by brain derived neurotrophic factor (BDNF) (Nestler \& Carlezon, 2006). A major source of BDNF in the NAc is from the VTA (Berton et al., 2006), and the binding of BDNF to TrkB on dopaminergic nerve terminals in the NAc potentiates the release of dopamine (Goggi et al., 2003). Berton et al. (2006) showed that male C57B1/6 mice exposed to social defeat exhibited decreased social interaction and increased BDNF in NAc. Viral expression of Cre in VTA dopamine neurons of floxed $B d n f$ mice blocked the development of social withdrawal after social defeat (Berton et al., 2006). Furthermore, only susceptible mice had increased BDNF in the NAc, and infusion of BDNF into the NAc enhanced susceptibility to defeat stress, while blocking ERK signaling (a downstream pathway of BDNF receptor TRKB) promoted resilience (Krishnan et al., 2007). Similarly, male rats subjected to intermittent social defeat stress also had increased BDNF positive cells in the NAc (Nikulina et al., 2012). Altogether, these findings suggest that susceptibility is facilitated by a defeat-induced increase in VTA activity, leading to an increase in BDNF in the NAc. In contrast, resilience is facilitated by inhibiting activity of VTA dopamine neurons. For example, changes in ion channel expression induced by repeated optical stimulation of the VTA can decrease firing rate and increase resilience to defeat stress (Friedman et al., 2014). BDNF release in the NAc may be a mechanism to promote neuroplasticity in the face of a stressor, but continued release after chronic stress may promote depression-like behaviors.

Several lines of evidence suggest that social defeat also affects the VTA-NAc circuit in females. Campi et al. (2014) reported higher total dopamine and HVA content in NAc punch samples from stressed female and male California mice compared to controls. Similarly, after a cocaine challenge, intermittently defeated female rats exhibited a sustained increase in dopamine release in the NAc compared to a short-term increase in defeated males (see Figure 2) (Holly et al., 
2012). Also after a cocaine challenge, susceptible female rats had significantly higher dopamine and serotonin release in the NAc compared to resilient females (Shimamoto et al., 2015). Moreover, two weeks after exposure to social defeat stress, both stressed and control females displayed increased TH/c-fos colocalizations across the entire VTA compared to males (Greenberg et al., 2015). However, c-fos immunoreactivity is probably not the optimal technique to examine long-term changes in activity and perhaps there is a different marker that would be more useful. These results are consistent with the results from males indicating that resilience to defeat is associated with blunted responses of VTA dopamine neurons.

An analysis of D1 receptor gene expression in the NAc and PFC showed no effects of defeat in male or female California mice (Campi et al., 2014). The role of D1 receptors was investigated because defeat stress induces an increase in phosphorylated CREB in the NAc shell of females but not males (Trainor et al., 2011). Activation of D1 receptors increases cAMP which in turn leads to CREB phosphorylation. A D1 receptor agonist directly infused into the NAc decreased social interaction in unstressed females, but not males, while D1 receptor antagonist infusions increased social interaction in stressed females (Campi et al., 2014). These results suggest that defeat-induced hyperactivity in the VTA-NAc circuit may generalize to female California mice. Interestingly, these results also show that D1-like receptor activation in the NAc is both necessary and sufficient to produce stress-induced social withdrawal in females, but not males. The sex difference in the of role D1-like receptors in social interaction behavior does not appear to occur at the level of receptor gene expression in the NAc because there were no sex differences in D1 receptor gene expression. In addition, both stressed males and females had increased levels of dopamine metabolites (Campi et al., 2014), suggesting no sex differences in dopamine breakdown. Together these results suggest that the sex difference in how defeat affects social interaction is mediated through a mechanism downstream of D1-like receptors. One pathway that may be engaged by the activation of D1 neurons is the kappa opioid receptor (KOR) system. Medium spiny neurons that express D1 receptors co-express dynorphin, the primary endogenous ligand for KOR (Hara et al., 2006). KORs are important modulators of other neurotransmitters. For example, KOR activation enhances serotonin reuptake (Schindler et al., 2012), which could, in turn, modulate social interaction. 
Exciting recent research has begun to investigate how gene regulation within the NAc underlies the effect of stress on motivated behaviors in males and females. Hodes et al. (2015) used RNAseq analysis in the NAc to show that subchronic variable stress (SCVS) induces vastly different changes in gene expression in female versus male C57B1/6 mice. In female mice, no study has successfully used social defeat stress, so SCVS has emerged as important model of stressinduced psychiatric disease. When subjected to SCVS, female, but not male, C57B1/6 mice show depression-like behaviors (LaPlant et al., 2009; Hodes et al., 2015). Interestingly, one of the genes that was upregulated in only females after SCVS was DNA methyltransferase 3a (Dnmt3a) which points to epigenetic mechanisms of gene regulation in sex differences. Knocking out Dnmt $3 a$ in the NAc promotes resilience in females and upregulating Dnmt3a produces prodepression-like behavior in both males and females exposed to a sub-threshold regimen of variable stress (LaPlant et al., 2010; Hodes et al., 2015). In the NAc, although there are some transcriptional similarities between Dnmt3a KO females (i.e. resilient females) and resilient males, there are many differences in upregulated and downregulated genes in resilient males and females showing similar phenotypes (Hodes et al., 2015). This indicates a possible sexdependent mechanism involved in susceptibility to stress. Corroborating the Dnmt3a data in mice, in human NAc Dnmt3a is elevated in both male and female patients with depression and shows a trend to decrease with treatment with antidepressants (Hodes et al., 2015). Further research is needed to investigate other candidate genes important in stress resilience and susceptibility in males and females and whether changes in gene expression are similar in animals subjected social defeat stress.

\section{EFFECTS OF SOCIAL DEFEAT ON THE BED NUCLEUS OF THE STRIA TERMINALIS}

The bed nucleus of the stria terminalis (BNST) is an important brain region for integrating information from the mesolimbic dopamine system and the social behavior network (O'Connell \& Hofmann, 2011). It has connections to the VTA and amygdala, and has been shown to be important in the development of psychiatric disorders such as post-traumatic stress disorder and social anxiety (Lebow \& Chen, 2016). Additionally, portions of the BNST are sexually dimorphic in both humans and rodents, with males having a larger volume than females and a different neurochemical distribution (Allen \& Gorski, 1990; Han \& De Vries, 2003; Campi et al., 
2013; Lebow \& Chen, 2016). Therefore, the BNST may play an important role in the development and treatment of stress-induced psychiatric disorders that affect males and females disproportionately.

The BNST strongly influences the expression of conditioned defeat in male hamsters. Infusion of the $\mathrm{GABA}_{\mathrm{A}}$ agonist muscimol $(1.1$ or $2.2 \mathrm{nmol})$ into the anterolateral BNST of male hamsters prior to social defeat does not affect submissive behavior during conditioned defeat testing (Markham et al., 2009). However, infusion of muscimol prior to conditioned defeat testing causes a significant decrease in submissive behaviors and an increase in non-social behaviors (e.g., locomotion, exploration, and grooming) (Markham et al., 2009). It has also been demonstrated that infusion of a corticotrophin releasing factor receptor antagonist, D-Phe $\mathrm{CRF}_{(12-41)}(250 \mathrm{ng})$, into the BNST prior to conditioned defeat testing blocks the expression of submissive behavior in male hamsters exposed to social defeat (Jasnow et al., 2004). These studies indicate that the anterolateral BNST is critical in the expression of conditioned defeat in male hamsters. Investigations of the relationship between social defeat and the BNST in females reveal long-term changes in more anterior regions of the BNST.

In general, the anterior BNST is not noted for being sexually dimorphic, but important sex differences in the effect of defeat on BDNF were discovered in anterior subregions of the BNST. After experiencing three days of social defeat stress, there is a significant increase in BDNF protein, but not mRNA, in the anterior subregions of the BNST in female, but not male, California mice (Greenberg et al., 2014). Increased BDNF protein in stressed females is normalized by chronic, but not acute, sertraline treatment, which also normalizes social interaction behavior (Greenberg et al., 2014). Furthermore, infusion of the specific TrkB antagonist ANA-12 (3 $\mu \mathrm{g})$ into the anterior BNST blocks the effect of social defeat on social interaction in stressed females, providing direct evidence that this stress-induced molecular change contributes to the social withdrawal phenotype. In contrast to studies done in male C57Bl/6, defeat stress does not induce changes in the adjacent NAc of stressed female California mice (Greenberg et al., 2014). Currently, the mechanism for increased BDNF protein expression in the BNST without a corresponding increase in mRNA is unknown. One possibility is that 
BDNF protein in the BNST is synthesized elsewhere, similar to how BDNF in the NAc appears to originate from VTA dopamine neurons.

The effects of stress in BNST might alter behavior in other contexts of motivated behavior, as well. For example, in males, there is evidence that repeated exposure to alcohol and stressors sensitizes corticotropin releasing factor activity in the BNST, leading to anxiety-like behaviors during withdrawal and increasing the likelihood of stressed-induced alcohol reinstatement (Silberman \& Winder, 2013). However, the effect of social defeat stress on alcohol consumption in females has not been examined.

\section{CONCLUSION}

Understanding how stress affects neurobiological systems associated with psychological disorders is an essential step for translational work that can lead to the development of new therapeutic approaches. Social defeat stress methods have provided important insights into the neurobiological mechanisms contributing to behavioral phenotypes such as social withdrawal and anhedonia. New approaches that allow for the examination of these mechanisms in females have already yielded important discoveries. In some cases males and females respond similarly to defeat stress; work in female California mice supports the hypothesis that defeat induces hyperactivity in the VTA-NAc circuit as has been observed in male mice and rats. Important sex differences have also be observed. In general females self-administer drugs of abuse more readily than males (Becker \& Koob, 2016), and psychosocial stress can enhance this process. Interestingly, after social defeat stress, sex differences in rat cocaine administration were not evident until 12 hours into a binge session. Work in mice indicates that increased Dnmt $3 a$ expression in the NAc enhances female vulnerability to psychosocial stress. It seems likely that delayed sex differences in behavior following social defeat stress could be mediated by epigenetic processes. Sex differences in behavioral responses to social defeat are also mediated by the BNST. However, it is the anterior subregions of the BNST (which are not sexually dimorphic at the anatomical level) that mediate stress-induced social withdrawal in females and not the sexually dimorphic posterior subregions of the BNST. These studies in rodents have provided valuable insights into neurobiological mechanisms that may also be present in humans. 
Translating these results to the human condition will be challenging. Currently it is not feasible to perform electrophysiological recordings on human VTA dopamine neurons and it is only possible to examine subregions of BNST in humans using post-mortem tissue samples. However, other model systems could provide a valuable bridge. For example, examination of socially subordinate female cynomolgus monkeys, which display depression-like behaviors (Willard et al., 2013), provides a unique perspective on how social stressors affect brain and behavior in a species that has a complex social system more like humans. While primate systems more closely resemble the human condition, rodent models provide more opportunity for mechanistic analysis. Conducting basic and translational research in a broad range of model systems provides a better understanding of how mechanisms of behavior are conserved across species. The commonalities that emerge provide the most promising directions for devising new approaches for treating mental illness. Social defeat models in California mice, rats, and hamsters provide an opportunity to examine these mechanisms in both males and females.

\section{Conflict of Interest Statement}

Neither author has a conflict of interest.

\section{Role of Authors}

$\mathrm{ALM}$ and BCT wrote the manuscript together. 


\section{Literature Cited}

Allen, L.S. \& Gorski, R.A. (1990) Sex difference in the bed nucleus of the stria terminalis of the human brain. The Journal of comparative neurology, 302, 697-706.

Anker, J.J. \& Carroll, M.E. (2011) Females are more vulnerable to drug abuse than males: evidence from preclinical studies and the role of ovarian hormones. Current topics in behavioral neurosciences, 8, 73-96.

Bardo, M.T. \& Bevins, R.A. (2000) Conditioned place preference: what does it add to our preclinical understanding of drug reward? Psychopharmacology, 153, 31-43.

Bath, K.G. \& Johnston, R.E. (2007) Dominant-subordinate relationships in hamsters: sex differences in reactions to familiar opponents. Hormones and behavior, 51, 258-264.

Becker, J.B. \& Koob, G.F. (2016) Sex Differences in Animal Models: Focus on Addiction. Pharmacological reviews, 68, 242-263.

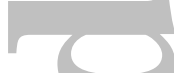

Berridge, K.C., Robinson, T.E. \& Aldridge, J.W. (2009) Dissecting components of reward: 'liking', 'wanting', and learning. Current opinion in pharmacology, 9, 65-73.

Berton, O., McClung, C.A., Dileone, R.J., Krishnan, V., Renthal, W., Russo, S.J., Graham, D., Tsankova, N.M., Bolanos, C.A., Rios, M., Monteggia, L.M., Self, D.W. \& Nestler, E.J. (2006) Essential role of BDNF in the mesolimbic dopamine pathway in social defeat stress. Science, 311, 864-868.

Brischoux, F., Chakraborty, S., Brierley, D.I. \& Ungless, M.A. (2009) Phasic excitation of dopamine neurons in ventral VTA by noxious stimuli. Proceedings of the National Academy of Sciences of the United States of America, 106, 4894-4899.

Buwalda, B., Kole, M.H., Veenema, A.H., Huininga, M., de Boer, S.F., Korte, S.M. \& Koolhaas, J.M. (2005) Long-term effects of social stress on brain and behavior: a focus on hippocampal functioning. Neuroscience and biobehavioral reviews, 29, 83-97.

Campi, K.L., Greenberg, G.D., Kapoor, A., Ziegler, T.E. \& Trainor, B.C. (2014) Sex differences in effects of dopamine D1 receptors on social withdrawal. Neuropharmacology, 77, 208-216.

Campi, K.L., Jameson, C.E. \& Trainor, B.C. (2013) Sexual Dimorphism in the Brain of the Monogamous California Mouse (Peromyscus californicus). Brain, behavior and evolution, 81, 236-249. 
Cao, J.L., Covington, H.E., 3rd, Friedman, A.K., Wilkinson, M.B., Walsh, J.J., Cooper, D.C., Nestler, E.J. \& Han, M.H. (2010) Mesolimbic dopamine neurons in the brain reward circuit mediate susceptibility to social defeat and antidepressant action. The Journal of neuroscience : the official journal of the Society for Neuroscience, 30, 16453-16458.

Chaudhury, D., Walsh, J.J., Friedman, A.K., Juarez, B., Ku, S.M., Koo, J.W., Ferguson, D., Tsai, H.C., Pomeranz, L., Christoffel, D.J., Nectow, A.R., Ekstrand, M., Domingos, A., Mazei-Robison, M.S., Mouzon, E., Lobo, M.K., Neve, R.L., Friedman, J.M., Russo, S.J., Deisseroth, K., Nestler, E.J. \& Han, M.H. (2013) Rapid regulation of depression-related behaviours by control of midbrain dopamine neurons. Nature, 493, 532-536.

Cooper, M.A., Clinard, C.T. \& Morrison, K.E. (2015) Neurobiological mechanisms supporting experiencedependent resistance to social stress. Neuroscience, 291, 1-14.

Covington, H.E., 3rd \& Miczek, K.A. (2005) Intense cocaine self-administration after episodic social defeat stress, but not after aggressive behavior: dissociation from corticosterone activation. Psychopharmacology, 183, 331-340.

Friedman, A.K., Walsh, J.J., Juarez, B., Ku, S.M., Chaudhury, D., Wang, J., Li, X., Dietz, D.M., Pan, N., Vialou, V.F., Neve, R.L., Yue, Z. \& Han, M.H. (2014) Enhancing depression mechanisms in midbrain dopamine neurons achieves homeostatic resilience. Science, 344, 313-319.

Fuxjager, M.J., Mast, G., Becker, E.A. \& Marler, C.A. (2009) The 'home advantage' is necessary for a full winner effect and changes in post-encounter testosterone. Hormones and behavior, 56, 214219.

Goggi, J., Pullar, I.A., Carney, S.L. \& Bradford, H.F. (2003) Signalling pathways involved in the short-term potentiation of dopamine release by BDNF. Brain research, 968, 156-161.

Golden, S.A., Covington, H.E., 3rd, Berton, O. \& Russo, S.J. (2011) A standardized protocol for repeated social defeat stress in mice. Nature protocols, 6, 1183-1191.

Gray, C.L., Norvelle, A., Larkin, T. \& Huhman, K.L. (2015) Dopamine in the nucleus accumbens modulates the memory of social defeat in Syrian hamsters (Mesocricetus auratus). Behavioural brain research, 286, 22-28.

Greenberg, G.D., Laman-Maharg, A., Campi, K.L., Voigt, H., Orr, V.N., Schaal, L. \& Trainor, B.C. (2014) Sex differences in stress-induced social withdrawal: role of brain derived neurotrophic factor in the bed nucleus of the stria terminalis. Frontiers in behavioral neuroscience, 7, 223. 
Greenberg, G.D., Steinman, M.Q., Doig, I.E., Hao, R. \& Trainor, B.C. (2015) Effects of social defeat on dopamine neurons in the ventral tegmental area in male and female California mice. The European journal of neuroscience.

Hammels, C., Pishva, E., De Vry, J., van den Hove, D.L., Prickaerts, J., van Winkel, R., Selten, J.P., Lesch, K.P., Daskalakis, N.P., Steinbusch, H.W., van Os, J., Kenis, G. \& Rutten, B.P. (2015) Defeat stress

in rodents: From behavior to molecules. Neuroscience and biobehavioral reviews, 59, 111-140.

Han, T.M. \& De Vries, G.J. (2003) Organizational effects of testosterone, estradiol, and dihydrotestosterone on vasopressin mRNA expression in the bed nucleus of the stria terminalis. Journal of neurobiology, 54, 502-510.

Han, X., Albrechet-Souza, L., Doyle, M.R., Shimamoto, A., DeBold, J.F. \& Miczek, K.A. (2015) Social stress and escalated drug self-administration in mice II. Cocaine and dopamine in the nucleus accumbens. Psychopharmacology, 232, 1003-1010.

Haney, M., Maccari, S., Le Moal, M., Simon, H. \& Piazza, P.V. (1995) Social stress increases the acquisition of cocaine self-administration in male and female rats. Brain research, 698, 46-52.

Hara, Y., Yakovleva, T., Bakalkin, G. \& Pickel, V.M. (2006) Dopamine D1 receptors have subcellular distributions conducive to interactions with prodynorphin in the rat nucleus accumbens shell. Synapse, 60, 1-19.

Hodes, G.E., Pfau, M.L., Purushothaman, I., Ahn, H.F., Golden, S.A., Christoffel, D.J., Magida, J., Brancato, A., Takahashi, A., Flanigan, M.E., Menard, C., Aleyasin, H., Koo, J.W., Lorsch, Z.S., Feng, J., Heshmati, M., Wang, M., Turecki, G., Neve, R., Zhang, B., Shen, L., Nestler, E.J. \& Russo, S.J. (2015) Sex Differences in Nucleus Accumbens Transcriptome Profiles Associated with Susceptibility versus Resilience to Subchronic Variable Stress. The Journal of neuroscience : the official journal of the Society for Neuroscience, 35, 16362-16376.

Hofmann, H.A. \& Stevenson, P.A. (2000) Flight restores fight in crickets. Nature, 403, 613.

Hollis, F., Wang, H., Dietz, D., Gunjan, A. \& Kabbaj, M. (2010) The effects of repeated social defeat on long-term depressive-like behavior and short-term histone modifications in the hippocampus in male Sprague-Dawley rats. Psychopharmacology, 211, 69-77.

Holly, E.N., Shimamoto, A., Debold, J.F. \& Miczek, K.A. (2012) Sex differences in behavioral and neural cross-sensitization and escalated cocaine taking as a result of episodic social defeat stress in rats. Psychopharmacology, 224, 179-188. 
Huhman, K.L., Solomon, M.B., Janicki, M., Harmon, A.C., Lin, S.M., Israel, J.E. \& Jasnow, A.M. (2003) Conditioned defeat in male and female Syrian hamsters. Hormones and behavior, 44, 293-299.

Hymel, K.A., Eans, S.O., K, L.S., Gomes, S.M., Lukowsky, A.L., Medina, J.M., Sypek, E.I., Carey, A.N. \& McLaughlin, J.P. (2014) Stress-induced increases in depression-like and cocaine placeconditioned behaviors are reversed by disruption of memories during reconsolidation.

Behavioural pharmacology, 25, 599-608.

Iniguez, S.D., Vialou, V., Warren, B.L., Cao, J.L., Alcantara, L.F., Davis, L.C., Manojlovic, Z., Neve, R.L., Russo, S.J., Han, M.H., Nestler, E.J. \& Bolanos-Guzman, C.A. (2010) Extracellular signal-regulated

kinase-2 within the ventral tegmental area regulates responses to stress. The Journal of neuroscience : the official journal of the Society for Neuroscience, 30, 7652-7663.

Jackson, L.R., Robinson, T.E. \& Becker, J.B. (2006) Sex differences and hormonal influences on acquisition of cocaine self-administration in rats. Neuropsychopharmacology : official publication of the American College of Neuropsychopharmacology, 31, 129-138.

Jasnow, A.M., Davis, M. \& Huhman, K.L. (2004) Involvement of central amygdalar and bed nucleus of the stria terminalis corticotropin-releasing factor in behavioral responses to social defeat. Behavioral neuroscience, 118, 1052-1061.

Jasnow, A.M. \& Huhman, K.L. (2001) Activation of GABA(A) receptors in the amygdala blocks the acquisition and expression of conditioned defeat in Syrian hamsters. Brain research, 920, 142150.

Jeffress, E.C. \& Huhman, K.L. (2013) Copulatory and agonistic behavior in Syrian hamsters following social defeat. Aggressive behavior, 39, 239-245.

Kessler, R.C. (2003) Epidemiology of women and depression. Journal of affective disorders, 74, 5-13.

Kessler, R.C., Chiu, W.T., Demler, O., Merikangas, K.R. \& Walters, E.E. (2005) Prevalence, severity, and comorbidity of 12-month DSM-IV disorders in the National Comorbidity Survey Replication. Archives of general psychiatry, 62, 617-627.

Krishnan, V., Han, M.H., Graham, D.L., Berton, O., Renthal, W., Russo, S.J., Laplant, Q., Graham, A., Lutter, M., Lagace, D.C., Ghose, S., Reister, R., Tannous, P., Green, T.A., Neve, R.L., Chakravarty, S., Kumar, A., Eisch, A.J., Self, D.W., Lee, F.S., Tamminga, C.A., Cooper, D.C., Gershenfeld, H.K. \& Nestler, E.J. (2007) Molecular adaptations underlying susceptibility and resistance to social defeat in brain reward regions. Cell, 131, 391-404. 
Kudryavtseva, N.N., Bakshtanovskaya, I.V. \& Koryakina, L.A. (1991) Social model of depression in mice of C57BL/6J strain. Pharmacology, biochemistry, and behavior, 38, 315-320.

Kudryavtseva, N.N., Gerrits, M.A., Avgustinovich, D.F., Tenditnik, M.V. \& Van Ree, J.M. (2004) Modulation of anxiety-related behaviors by mu- and kappa-opioid receptor agonists depends on the social status of mice. Peptides, 25, 1355-1363.

Land, B.B., Bruchas, M.R., Schattauer, S., Giardino, W.J., Aita, M., Messinger, D., Hnasko, T.S., Palmiter, R.D. \& Chavkin, C. (2009) Activation of the kappa opioid receptor in the dorsal raphe nucleus mediates the aversive effects of stress and reinstates drug seeking. Proceedings of the National Academy of Sciences of the United States of America, 106, 19168-19173.

LaPlant, Q., Chakravarty, S., Vialou, V., Mukherjee, S., Koo, J.W., Kalahasti, G., Bradbury, K.R., Taylor, S.V., Maze, I., Kumar, A., Graham, A., Birnbaum, S.G., Krishnan, V., Truong, H.T., Neve, R.L., Nestler, E.J. \& Russo, S.J. (2009) Role of nuclear factor kappaB in ovarian hormone-mediated stress hypersensitivity in female mice. Biological psychiatry, 65, 874-880.

LaPlant, Q., Vialou, V., Covington, H.E., 3rd, Dumitriu, D., Feng, J., Warren, B.L., Maze, I., Dietz, D.M.,

Watts, E.L., Iniguez, S.D., Koo, J.W., Mouzon, E., Renthal, W., Hollis, F., Wang, H., Noonan, M.A., Ren, Y., Eisch, A.J., Bolanos, C.A., Kabbaj, M., Xiao, G., Neve, R.L., Hurd, Y.L., Oosting, R.S., Fan, G., Morrison, J.H. \& Nestler, E.J. (2010) Dnmt3a regulates emotional behavior and spine plasticity in the nucleus accumbens. Nature neuroscience, 13, 1137-1143.

Lebow, M.A. \& Chen, A. (2016) Overshadowed by the amygdala: the bed nucleus of the stria terminalis emerges as key to psychiatric disorders. Molecular psychiatry.

Liu, Y., Yang, L., Yu, J. \& Zhang, Y.Q. (2015) Persistent, comorbid pain and anxiety can be uncoupled in a mouse model. Physiology \& behavior, 151, 55-63.

Lukas, M., Toth, I., Reber, S.O., Slattery, D.A., Veenema, A.H. \& Neumann, I.D. (2011) The neuropeptide oxytocin facilitates pro-social behavior and prevents social avoidance in rats and mice. Neuropsychopharmacology : official publication of the American College of Neuropsychopharmacology, 36, 2159-2168.

Markham, C.M., Norvelle, A. \& Huhman, K.L. (2009) Role of the bed nucleus of the stria terminalis in the acquisition and expression of conditioned defeat in Syrian hamsters. Behavioural brain research, $198,69-73$.

McLaughlin, J.P., Li, S., Valdez, J., Chavkin, T.A. \& Chavkin, C. (2006) Social defeat stress-induced behavioral responses are mediated by the endogenous kappa opioid system. 
Neuropsychopharmacology : official publication of the American College of Neuropsychopharmacology, 31, 1241-1248.

Meerlo, P., Overkamp, G.J., Daan, S., Van Den Hoofdakker, R.H. \& Koolhaas, J.M. (1996) Changes in Behaviour and Body Weight Following a Single or Double Social Defeat in Rats. Stress, 1, 21-32.

Miczek, K.A. \& Mutschler, N.H. (1996) Activational effects of social stress on IV cocaine selfadministration in rats. Psychopharmacology, 128, 256-264.

Miczek, K.A., Nikulina, E.M., Shimamoto, A. \& Covington, H.E., 3rd (2011) Escalated or suppressed cocaine reward, tegmental BDNF, and accumbal dopamine caused by episodic versus continuous social stress in rats. The Journal of neuroscience : the official journal of the Society for Neuroscience, 31, 9848-9857.

Montagud-Romero, S., Aguilar, M.A., Maldonado, C., Manzanedo, C., Minarro, J. \& Rodriguez-Arias, M. (2015) Acute social defeat stress increases the conditioned rewarding effects of cocaine in adult but not in adolescent mice. Pharmacology, biochemistry, and behavior, 135, 1-12.

Morrison, K.E., Bader, L.R., Clinard, C.T., Gerhard, D.M., Gross, S.E. \& Cooper, M.A. (2014) Maintenance of dominance status is necessary for resistance to social defeat stress in Syrian hamsters. Behavioural brain research, 270, 277-286.

Morrison, K.E., Curry, D.W. \& Cooper, M.A. (2012) Social status alters defeat-induced neural activation in Syrian hamsters. Neuroscience, 210, 168-178.

Morrison, K.E., Swallows, C.L. \& Cooper, M.A. (2011) Effects of dominance status on conditioned defeat and expression of 5-HT1A and 5-HT2A receptors. Physiology \& behavior, 104, 283-290.

Nestler, E.J. \& Carlezon, W.A., Jr. (2006) The mesolimbic dopamine reward circuit in depression. Biological psychiatry, 59, 1151-1159.

Nikulina, E.M., Lacagnina, M.J., Fanous, S., Wang, J. \& Hammer, R.P., Jr. (2012) Intermittent social defeat stress enhances mesocorticolimbic DeltaFosB/BDNF co-expression and persistently activates corticotegmental neurons: implication for vulnerability to psychostimulants. Neuroscience, 212, 38-48.

O'Connell, L.A. \& Hofmann, H.A. (2011) The vertebrate mesolimbic reward system and social behavior network: a comparative synthesis. The Journal of comparative neurology, 519, 3599-3639. 
Oyegbile, T.O. \& Marler, C.A. (2005) Winning fights elevates testosterone levels in California mice and enhances future ability to win fights. Hormones and behavior, 48, 259-267.

Panlilio, L.V. \& Goldberg, S.R. (2007) Self-administration of drugs in animals and humans as a model and an investigative tool. Addiction, 102, 1863-1870.

Patki, G., Solanki, N. \& Salim, S. (2014) Witnessing traumatic events causes severe behavioral impairments in rats. The international journal of neuropsychopharmacology / official scientific journal of the Collegium Internationale Neuropsychopharmacologicum, 17, 2017-2029.

Payne, A.P. \& Swanson, H.H. (1970) Agonistic behaviour between pairs of hamsters of the same and opposite sex in a neutral observation area. Behaviour, 36, 260-269.

Ribble, D.O. \& Salvioni, M. (1990) Social-Organization and Nest Co-Occupancy in PeromyscusCalifornicus, a Monogamous Rodent. Behav Ecol Sociobiol, 26, 9-15.

Ribeiro Do Couto, B., Aguilar, M.A., Lluch, J., Rodriguez-Arias, M. \& Minarro, J. (2009) Social experiences affect reinstatement of cocaine-induced place preference in mice. Psychopharmacology, 207, 485-498.

Savignac, H.M., Finger, B.C., Pizzo, R.C., O'Leary, O.F., Dinan, T.G. \& Cryan, J.F. (2011) Increased sensitivity to the effects of chronic social defeat stress in an innately anxious mouse strain. Neuroscience, 192, 524-536.

Schindler, A.G., Messinger, D.I., Smith, J.S., Shankar, H., Gustin, R.M., Schattauer, S.S., Lemos, J.C., Chavkin, N.W., Hagan, C.E., Neumaier, J.F. \& Chavkin, C. (2012) Stress produces aversion and potentiates cocaine reward by releasing endogenous dynorphins in the ventral striatum to locally stimulate serotonin reuptake. The Journal of neuroscience : the official journal of the Society for Neuroscience, 32, 17582-17596.

Shimamoto, A., Holly, E.N., Boyson, C.O., DeBold, J.F. \& Miczek, K.A. (2015) Individual differences in anhedonic and accumbal dopamine responses to chronic social stress and their link to cocaine self-administration in female rats. Psychopharmacology, 232, 825-834.

Sial, O.K., Warren, B.L., Alcantara, L.F., Parise, E.M. \& Bolanos-Guzman, C.A. (2016) Vicarious social defeat stress: Bridging the gap between physical and emotional stress. Journal of neuroscience methods, 258, 94-103. 
Silberman, Y. \& Winder, D.G. (2013) Emerging role for corticotropin releasing factor signaling in the bed nucleus of the stria terminalis at the intersection of stress and reward. Frontiers in psychiatry, 4, 42.

Sinha, R. (2008) Chronic stress, drug use, and vulnerability to addiction. Annals of the New York Academy of Sciences, 1141, 105-130.

Solomon, M.B., Karom, M.C. \& Huhman, K.L. (2007) Sex and estrous cycle differences in the display of conditioned defeat in Syrian hamsters. Hormones and behavior, 52, 211-219.

Steinman, M.Q., Laredo, S.A., Lopez, E.M., Manning, C.E., Hao, R.C., Doig, I.E., Campi, K.L., Flowers, A.E., Knight, J.K. \& Trainor, B.C. (2015) Hypothalamic vasopressin systems are more sensitive to the long term effects of social defeat in males versus females. Psychoneuroendocrinology, 51, 122134.

Tidey, J.W. \& Miczek, K.A. (1996) Social defeat stress selectively alters mesocorticolimbic dopamine release: an in vivo microdialysis study. Brain research, 721, 140-149.

Titomanlio, F., Manzanedo, C., Rodriguez-Arias, M., Mattioli, L., Perfumi, M., Minarro, J. \& Aguilar, M.A. (2013) Rhodiola rosea Impairs Acquisition and Expression of Conditioned Place Preference Induced by Cocaine. Evidence-based complementary and alternative medicine : eCAM, 2013, 697632.

Trainor, B.C., Pride, M.C., Villalon Landeros, R., Knoblauch, N.W., Takahashi, E.Y., Silva, A.L. \& Crean, K.K. (2011) Sex differences in social interaction behavior following social defeat stress in the monogamous California mouse (Peromyscus californicus). PloS one, 6, e17405.

Trainor, B.C., Takahashi, E.Y., Campi, K.L., Florez, S.A., Greenberg, G.D., Laman-Maharg, A., Laredo, S.A., Orr, V.N., Silva, A.L. \& Steinman, M.Q. (2013) Sex differences in stress-induced social withdrawal: independence from adult gonadal hormones and inhibition of female phenotype by corncob bedding. Hormones and behavior, 63, 543-550.

Vasconcelos, M., Stein, D.J. \& de Almeida, R.M. (2015) Social defeat protocol and relevant biomarkers, implications for stress response physiology, drug abuse, mood disorders and individual stress vulnerability: a systematic review of the last decade. Trends in psychiatry and psychotherapy, 37, 51-66.

Venzala, E., Garcia-Garcia, A.L., Elizalde, N., Delagrange, P. \& Tordera, R.M. (2012) Chronic social defeat stress model: behavioral features, antidepressant action, and interaction with biological risk factors. Psychopharmacology, 224, 313-325. 
Warren, B.L., Vialou, V.F., Iniguez, S.D., Alcantara, L.F., Wright, K.N., Feng, J., Kennedy, P.J., Laplant, Q., Shen, L., Nestler, E.J. \& Bolanos-Guzman, C.A. (2013) Neurobiological sequelae of witnessing stressful events in adult mice. Biological psychiatry, 73, 7-14.

Willard, S.L., Riddle, D.R., Forbes, M.E. \& Shively, C.A. (2013) Cell number and neuropil alterations in subregions of the anterior hippocampus in a female monkey model of depression. Biological psychiatry, 74, 890-897.

Yap, J.J., Chartoff, E.H., Holly, E.N., Potter, D.N., Carlezon, W.A., Jr. \& Miczek, K.A. (2015) Social defeat stress-induced sensitization and escalated cocaine self-administration: the role of ERK signaling in the rat ventral tegmental area. Psychopharmacology, 232, 1555-1569.

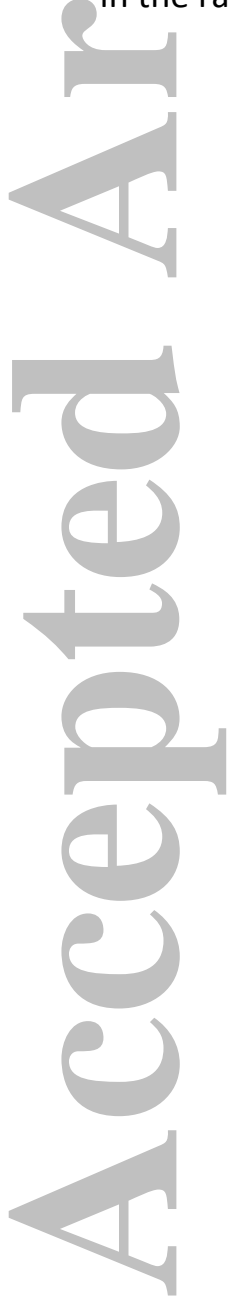




\section{Figure Legends:}

Figure 1. Social interaction behavior in male and female California mice four weeks after social defeat. In the apparatus used for testing (A), the interaction zone is indicated by a blue box and the corner zones indicated by red boxes. There were no significant differences when mice were tested with an empty cage (B). Females, but not males exposed to social defeat showed reduced social interaction behavior with a novel mouse (C). Immediately after the social interaction test mice were euthanized and vaginal lavage was conducted to determine estrous cycle stage. Social defeat reduced social interaction time at different stages of the estrous cycle (D). ** planned comparison control group versus stress group p,0.01. *** planned comparison control group versus stress group p,0.01. All data are mean \pm s.e. Reprinted from Trainor et al., 2011.

\section{Figure 2.}

Dopamine (DA) levels in the nucleus accumbens (NAc) expressed as percent change from baseline (BL) in the same animals in (a) intermittently stressed ( $n=7$, filled circles) or control $(n=5$, open circles) male rats and $(b)$ intermittently stressed $(n=7$, filled triangles) or control $(n=5$, open triangles) female rats. All values are means $\pm \mathrm{SEM} ; *=\mathrm{p}<0.05, * *=\mathrm{p}<0.01, * * *=\mathrm{p}<0.001$

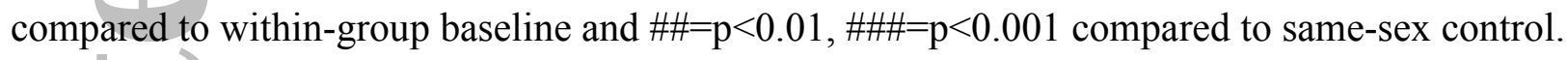
Reprinted from Holly et al., 2012 with permission from Springer. 
A

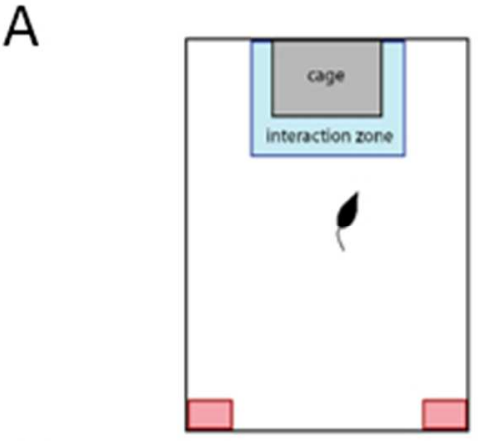

C

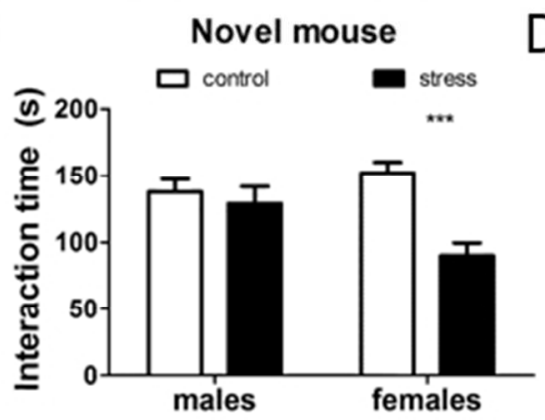

B

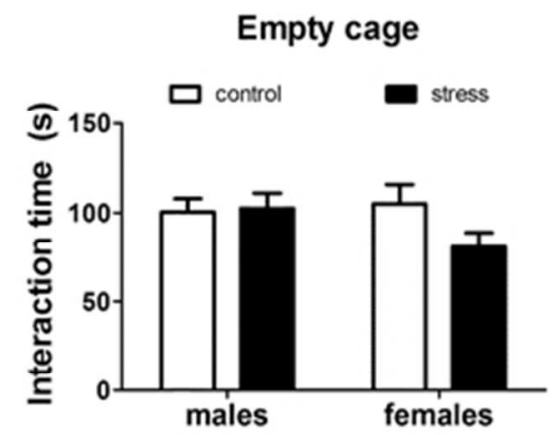

D

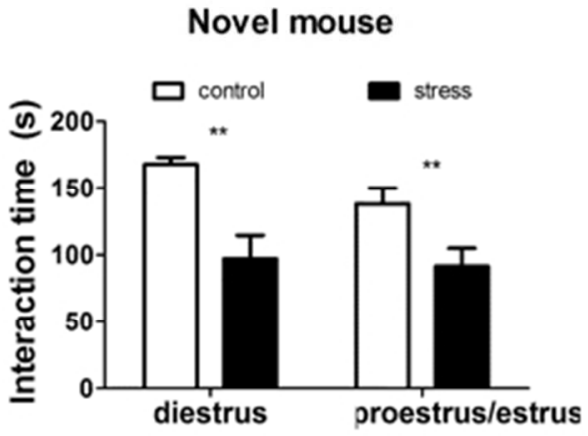

Figure 1. Social interaction behavior in male and female California mice four weeks after social defeat. In the apparatus used for testing $(A)$, the interaction zone is indicated by a blue box and the corner zones indicated

by red boxes. There were no significant differences when mice were tested with an empty cage (B).

Females, but not males exposed to social defeat showed reduced social interaction behavior with a novel

mouse (C). Immediately after the social interaction test mice were euthanized and vaginal lavage was conducted to determine estrous cycle stage. Social defeat reduced social interaction time at different stages

of the estrous cycle (D). ** planned comparison control group versus stress group $\mathrm{p}, 0.01$. *** planned comparison control group versus stress group $p, 0.01$. All data are mean \pm s.e. Reprinted from Trainor et al., 2011.

$49 \times 35 \mathrm{~mm}(300 \times 300$ DPI $)$ 
a. Males

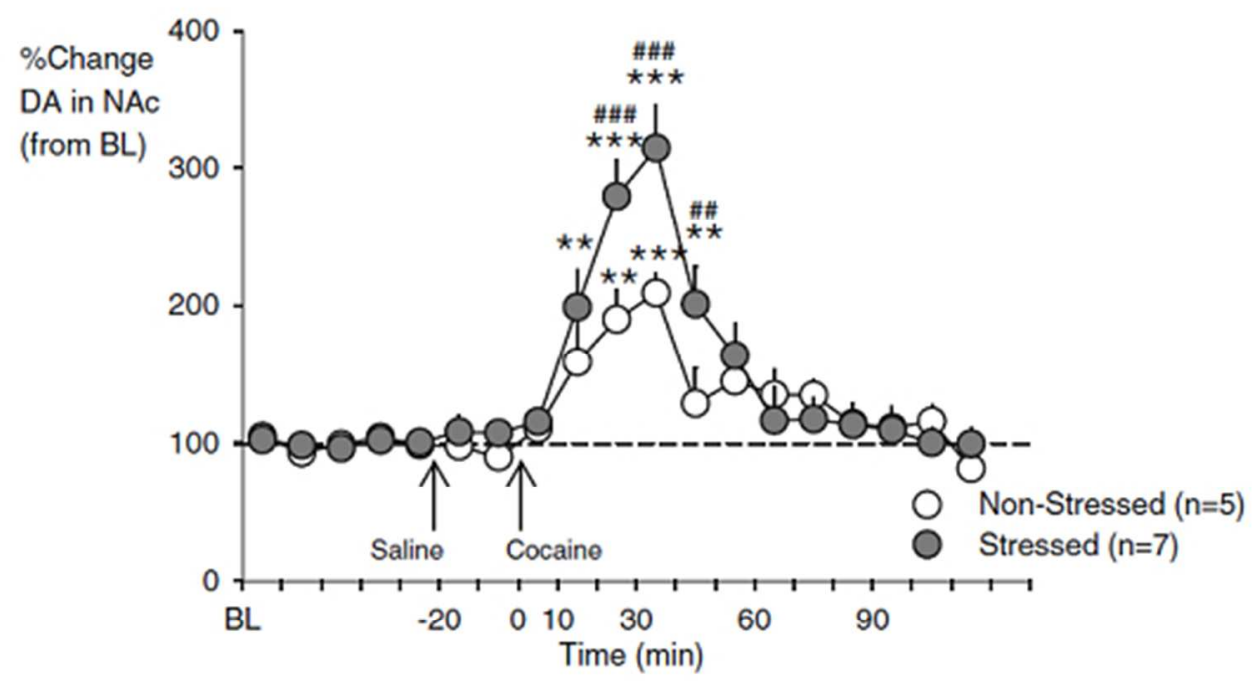

\section{b. Females}

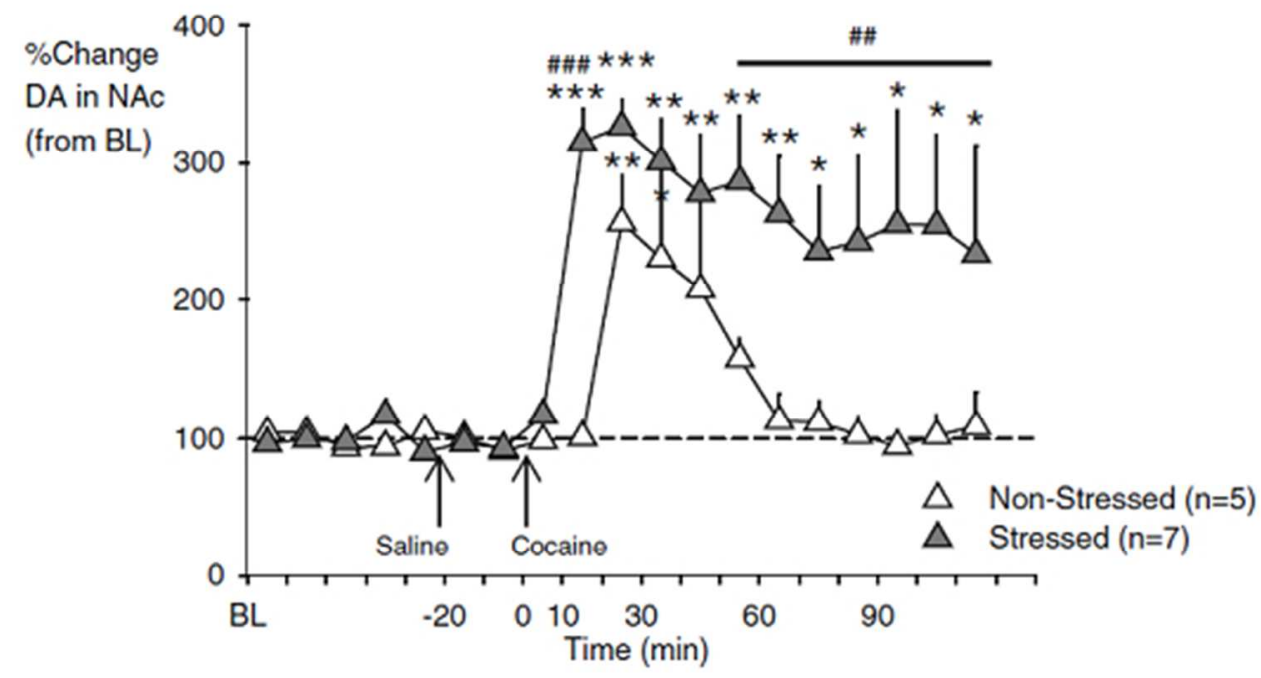

Dopamine (DA) levels in the nucleus accumbens (NAC) expressed as percent change from baseline (BL) in the same animals in (a) intermittently stressed ( $n=7$, filled circles) or control ( $n=5$, open circles) male rats and (b) intermittently stressed ( $n=7$, filled triangles) or control ( $n=5$, open triangles) female rats. All values are means $\pm \mathrm{SEM}^{*} *=\mathrm{p}<0.05, * *=\mathrm{p}<0.01, * * *=\mathrm{p}<0.001$ compared to within-group baseline and $\# \#=p<0.01$, \#\# \#=p<0.001 compared to same-sex control. Reprinted from Holly et al., 2012 with permission from Springer.

$46 \times 52 \mathrm{~mm}(300 \times 300 \mathrm{DPI})$ 